\title{
Penetrasi Papan Ketik Aksara Bali pada Pengguna Perangkat Mobile
}

\author{
Ida Bagus Ary Indra Iswara' ${ }^{1}$, Putu Praba Santika ${ }^{2}$, \\ I Nyoman Saputra Wahyu Wijaya ${ }^{3}$ \\ ${ }^{123}$ Teknik Informatika, STMIK STIKOM Indonesia \\ email: 19usari@stiki-indonesia.ac.id, 2praba@stiki-indonesia.ac.id, \\ 3wahyu@stiki-indonesia.ac.id
}

\begin{abstract}
The Balinese language which is used in daily life on the island of Bali has experienced a shift in usage so it needs to be preserved. In an effort to preserve the Balinese language and script, the Provincial Government issued Bali Governor Regulation Number 20 of 2013 and Regulation number 1 of 2018. I Made Suatjana submitted a proposal that the Balinese script be included in Unicode to make it easier to display Balinese script on digital media. Cokorda Rai Adi Pramartha developed keyboards or keyboards and an application called T@miang to facilitate typing Balinese characters on computer devices. Computer equipment is slowly becoming obsolete, replaced by mobile devices used by $53.03 \%$ of users in Indonesia, so it is necessary to build a Balinese script keyboard that can be used on mobile devices. PaTik Bali is built for mobile devices with Android operating system. PaTik Bali layout is adapted to T@miang keyboard layout. PaTik Bali version 1.0 only uses the Balinese script on each keyboard key. In version 2.0 each button on PaTik Bali has been added Latin letters because of the large number of entries on the Google Play page. Based on data recorded on the Google Play Console, there are 41,820 devices that have installed the Balinese Keyboard (PaTik Bali) application, 99.19\% are from Indonesia. In general, the PaTik Bali application can be accepted in the community, this can be seen from the average rating given by users on Google Play which is 4.27 on a scale of 5 . However, some users complain about the incorrect form of letters. The PaTik Bali application uses fonts that have been embedded in the Android operating system so that it can be used as a keyboard in other applications. This font still has enough problems. To fix this problem, it is necessary to develop the Balinese font then ask Google as an Android developer to enter the new font into the Android operating system.
\end{abstract}

Keywords: PaTik Bali, Virtual Keyboard, Penetration, Balinese Script

\section{LATAR BELAKANG}

Bahasa Bali digunakan sebagai bahasa alami yang digunakan dalam kehidupan sehari-hari di pulau Bali. Bali adalah salah satu bahasa yang sedang mengalami pergeseran penggunaan [1] Mengingat pentingnya pelestarian Bahasa Bali, pemerintah Provinsi Bali sudah berusaha melestarikan bahasa Bali dengan cara, salah satunya adalah dengan menerbitkan Peraturan Gubernur Bali Nomor 20 Tahun 2013 tentang bahasa, aksara dan sastra daerah Bali pada pendidikan dasar dan menengah. Pada Peraturan Gubernur Bali Nomor 20 Tahun 2013 disebutkan bahasa, aksara dan Sastra Bali diajarkan pada semua jenjang pendidikan dasar dan menengah sebagai mata pelajaran di Provinsi. Selain berdasarkan peraturan tersebut, saat ini peraturan tentang Bahasa Bali diperkuat dengan dikelurkanya Perda nomer 1 tahun 2018, tentang Bahasa, Aksara dan Sastra Bali [2] 
Tidak hanya pemerintah yang berusaha melestarikan bahasa dan aksara Bali, beberapa masyarakat juga berusaha untuk melestarikannya. Salah satunya adalah I Made Suatjana mengajukan proposal agar aksara Bali dimasukkan dalam Unicode atau ISO 10646. Kini aksara Bali sudah masuk dalam standar Unicode. Masuknya aksara Bali dalam Unicode sangat memudahkan untuk menampilkan aksara Bali dalam berbagai media. Aksara Bali memiliki keunikan dalam banyaknya huruf yang digunakan. Pada tahun 2014 Cokorda Rai Adi Pramartha mengembangkan perangkat masukkan berupa papan ketik atau keyboard dan aplikasi bernama T@miang untuk memudahkan pengguna dalam mengetik dan menggunakan aksara Bali pada perangkat komputer [3]. Tata letak tombol pada Tamiang disusun sesuai dengan tingkat penggunaan masing-masing karakter. Saat ini Tamiang baru dikembangkan pada perangkat Komputer dengan konsep multiplatform.

Seiring dengan perkembangan teknologi, perangkat komputer perlahan mulai ditinggalkan, berdasarkan statistic dari StatCounter [4] dari tahun Januari 2018 sampai Januari 2019, pengguna sistem operasi untuk perangkat komputer semakin jauh tertinggal. Pengguna sistem operasi windows untuk Indonesia sebanyak $33.73 \%$, sedangkan pengguna sistem operasi mobile menempati posisi pertama di Indonesia yaitu sekitar 53.03\%. Sistem operasi tersebut adalah sistem operasi android. Berdasarkan hal tersebut, kami ingin menyasar para pengguna android dalam mengimplementasikan aksara Bali dalam device mobile.

\section{PEMBAHASAN}

\section{Antar Muka Papan Ketik Aksara Bali (PaTik Bali)}

Aplikasi PaTik Bali dibangun dengan Android Studio. Pada aplikasi tersebut hanya menggunakan sebuah antarmuka yang dapat menampung keseluruhan karakter aksara Bali. Penempatan karakter aksara Bali pada tombol PaTik Bali disesuaikan dengan layout keyboard Tamiang. Untuk melakukan penginputan masing-masing aksara dilakukan dengan menyentuh layar sesuai dengan aksara yang diberikan. Selain itu terdapat pop up yang dapat diakses dengan menekan dan menahan pada salah satu aksara. Pop up ini digunakan untuk memilih aksara yang sama namun dalam variasi yang berbeda, contohnya ketika ingin memilih aksara na rambat, pengguna perlu menahan layar yang menunjukkan aksana na biasa.[5] Pada versi 1.0 antarmuka PaTik Bali dapat ditunjukkan pada Gambar 1 dan Gambar 2.

Pada Gambar 2 terlihat akan muncul beberapa varian lainnya dari aksara yang dipilih. Hal tersebut bertujuan untuk memudahkan pengguna dalam mencari aksara yang diinginkan. Pengguna tidak perlu lagi menggunakan tombol tambahan seperti ctrl dan alt seperti yang sudah diimplementasikan pada keyboard Tamiang Bali. Selain itu tujuannya adalah meminimalkan layer yang digunakan, hal tersebut mendukung alasan sebelumnya yaitu memberikan kemudahan kepada pengguna untuk mencari aksara yang diinginkan. PaTik Bali versi 1.0 seperti ditunjukkan pada Gambar 1 dan Gambar 2 hanya menggunakan aksara Bali pada setiap tombol papan ketiknya. Pada perkembangannya, ternyata tidak semua orang paham aksara Bali, termasuk orang Bali. Hal ini diketahui dari banyaknya komentar pada halaman Google Play yang meminta penambahan hurup latin pada setiap tombol papan ketik. Pada versi 2.0 setiap tombol pada PaTik Bali telah ditambahkan hurup latin. Antarmuka PaTik Bali versi 2.0 dapat dilihat pada Gambar 3. 

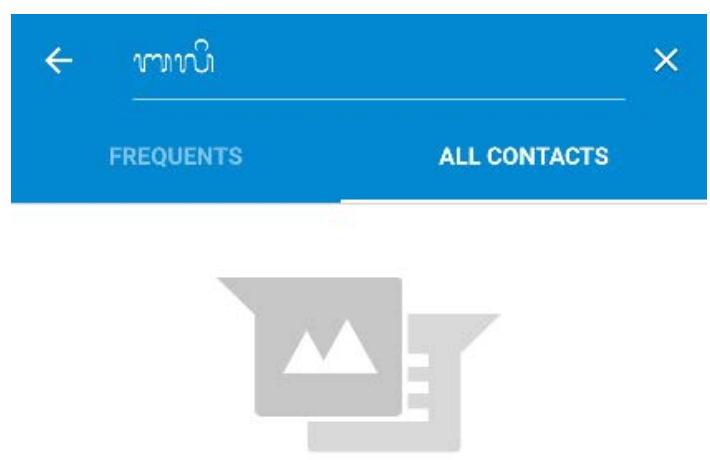

Enter a contact name or phone number to start a new message

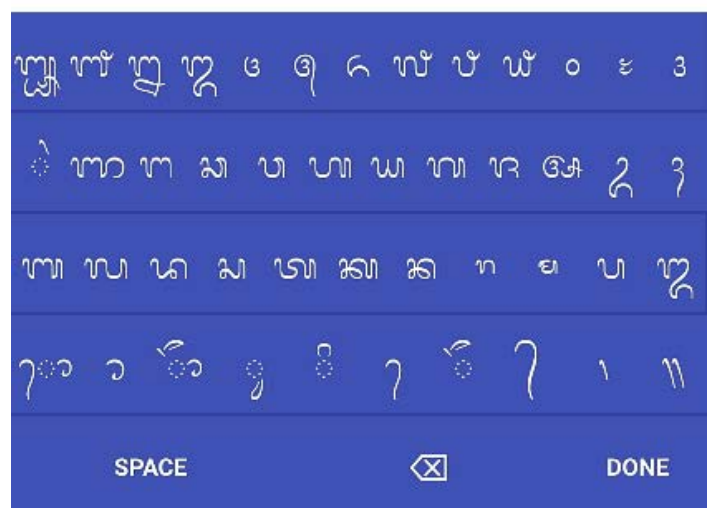

Gambar 1. Tampilan PaTik Bali versi 1.0

\section{PaTik Bali - Balinese Keyboard}

$\vdots$

Papan Ketik (PaTik) Aksara Bali

$$
\text { ขทขกิ| }
$$

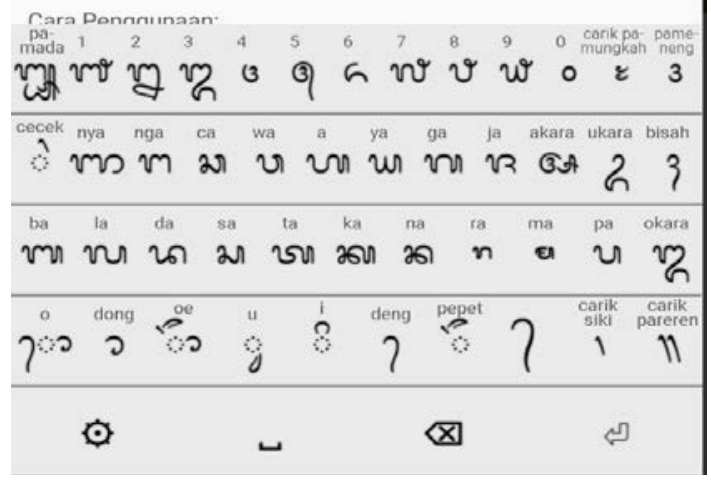

Gambar 3. Tampilan PaTik Bali versi 2.0
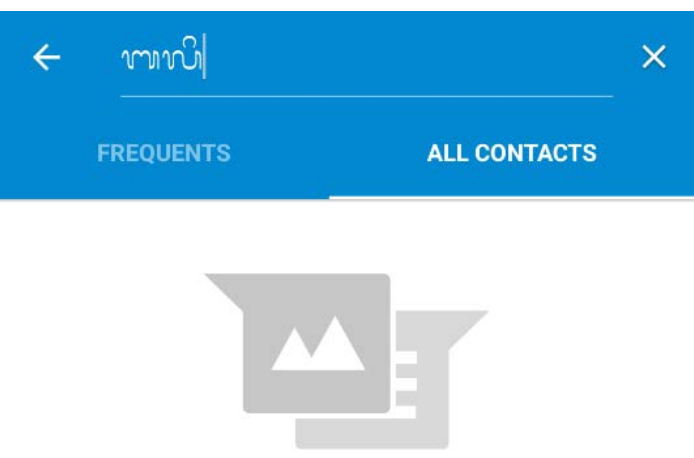

Enter a contact name or phone number to start a new message

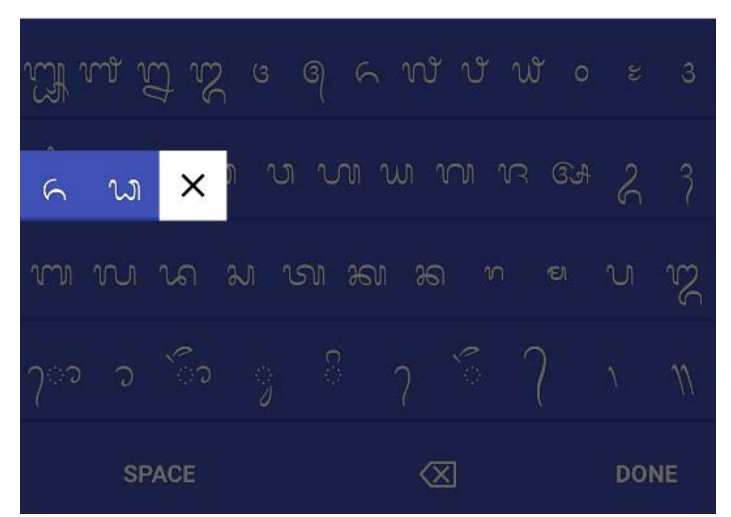

Gambar 2. Tampilan Pop Up PaTik Bali versi 1.0

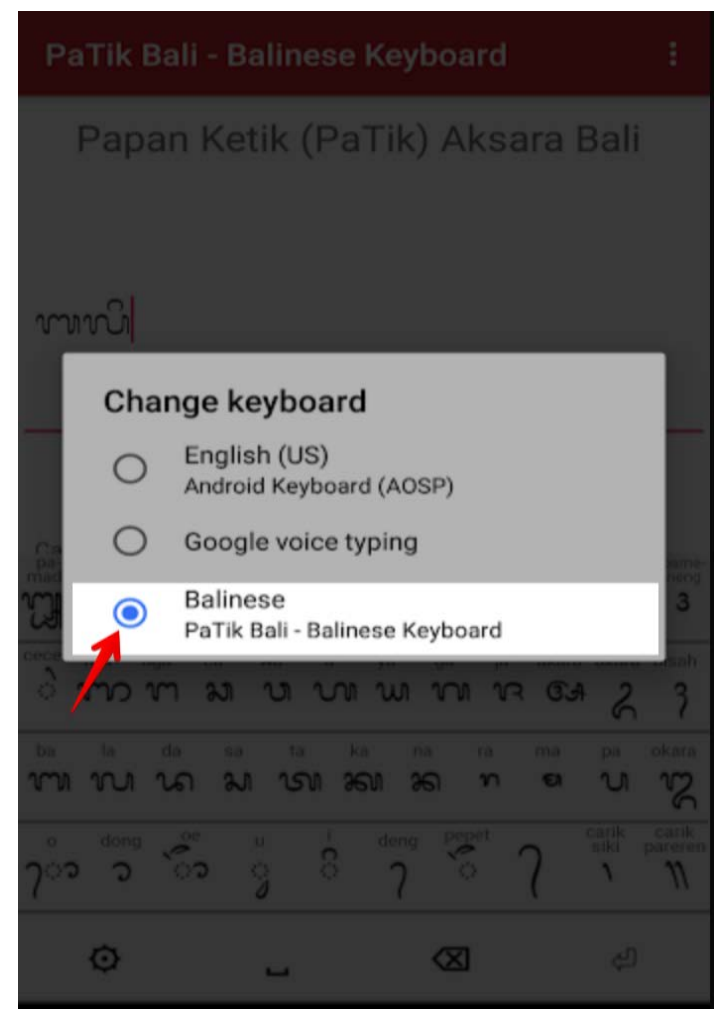

Gambar 4. Tampilan Mengganti keyboard PaTik Bali versi 2.0 


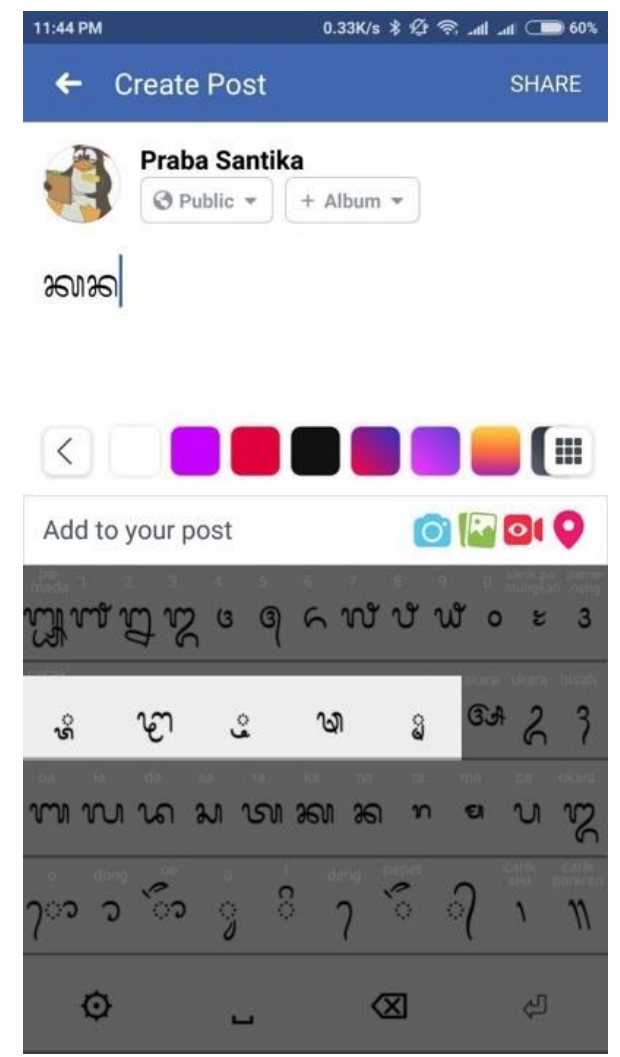

Gambar 5. Membuat Status Facebook dengan PaTik Bali

Selain penambahan huruf latin, pada versi 2.0 PaTik Bali juga dilengkapi dengan sebuah tombol setting yang mampu mengarahkan pengguna untuk memilih keyboard yang akan digunakan. Pembuatan tombol ini memudahkan pengguna untuk berganti keyboard, sehingga mungkin untuk mengkombinasikan antara Aksara Bali dengan huruf latin. Fitur ini dapat diakses dari tombol dengan icon gear, setelah dipilih akan muncul pop up, yang berisikan menu pemilihan keyboard seperti yang terlihat pada Gambar 4. Papan ketik Aksara Bali dapat digunakan sebagai keyboard pada semua semua inputan yang terdapat pada semua aplikasi android, seperti aplikasi sosial media, aplikasi chating, hingga aplikasi perkantoran. Seperti ditunjukkan pada Gambar 5 ditunjukkan aplikasi PaTik Bali digunakan untuk membuat status pada aplikasi sosial media Facebook.

Aplikasi Papan Ketik Aksara Bali (PaTik Bali) telah didaftarkan pada Kementerian Hukum dan Hak Asasi Manusia Republik Indonesia untuk mendapatkan Hak atas Kekayaan intelektual dengan nomor pendaftaran EC00201826152 pada tanggal 4 september 2018, dan tercatat dengan dengan nomor pencatatan 000116331.

\section{Sebaran Pengguna PaTiK Bali}

Pengguna aplikasi Papan Ketik Aksara Bali (PaTik Bali) sebagian besar berasal dari Indonesia. Berdasarkan data yang tercatat pada Google Play Console, 99,19\% pengguna yang menginstall aplikasi PaTik Bali berasal dari Indonesia. Hingga saat ini telah terdapat 41.820 perangkat yang menginstall aplikasi Papan Ketik Aksara Bali (PaTik Bali), grafik perkembangan penginstalan per hari terlihat pada Gambar 6.

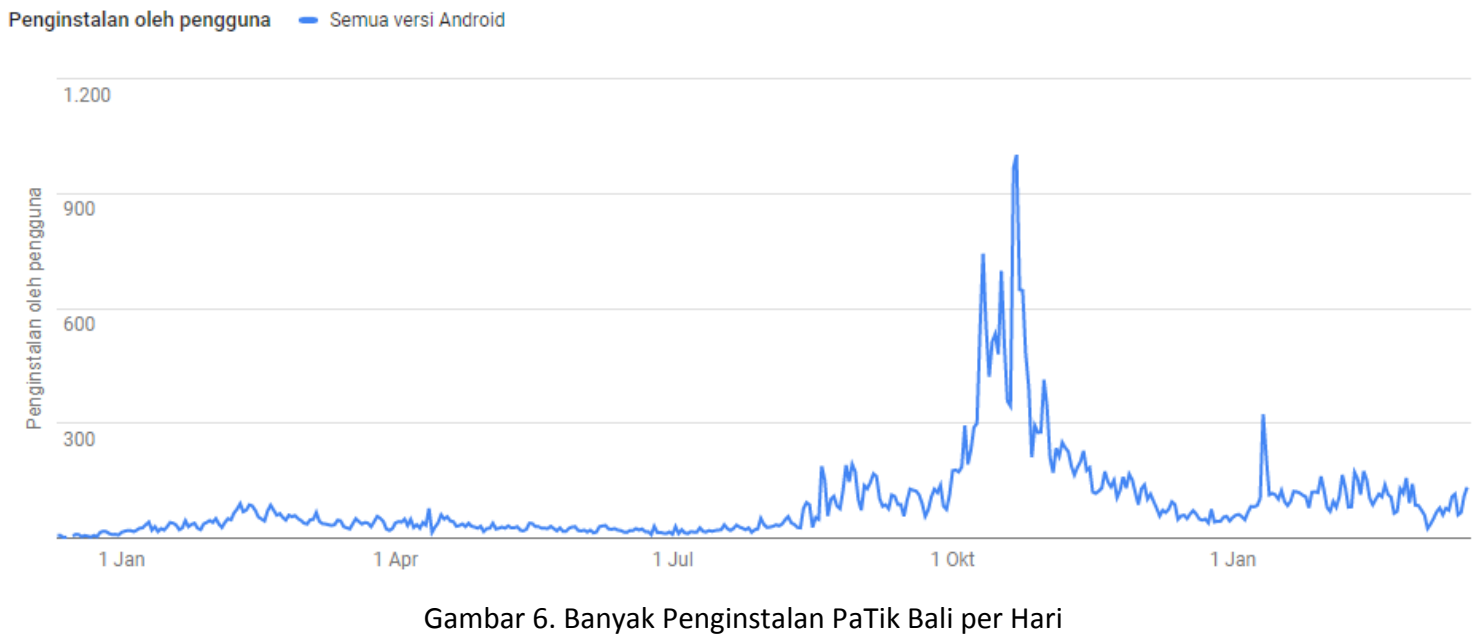


Pada Gambar 6 terlihat mulai terjadi peningkatan penginstal pada pertengahan bula Agustus, hal ini berkaitan dengan diluncurkannya versi uji coba PaTik Bali dengan penambahan hurup latin pada setiap tombolnya. Peninggkatan juga terjadi karena pada bulan Agustus 2018 tim pengembang PaTik Bali diundang dalam acara Technocorner dalam rangka Pameran Pebangunan Provinsi Bali, pada acara tersebut pengembang diberi kesempatan untuk memperkenalkan PaTik Bali kepada pengunjung Pamera Pembangunan Provinsi Bali. Pada bulan September PaTik Bali versi 2.0.1 diluncurkan. Pada versi 2.0.1 PaTik Bali terdapat perbaikan penempatan huruf latin sebagai pendamping aksara Bali untuk setiap tombolnya sehingga memudahkan bagi pengguna yang tidak terbiasa menggunakan aksara Bali. Pada bulan september dan oktober terjadi lonjakan yang sangat tinggi, karena tim pengembang PaTik Bali diundang untuk mengisi acara pada Radio Republik Indonesia, sehingga semakin banyak orang yang mengetahui keberadaan aplikasi ini.

Secara umum aplikasi PaTik Bali dapat diterima dimasyarakat, hal ini dapat dilihat dari rata-rata rating yang diberikan pengguna pada Google Palay. Menurut data yang diambil dari Google Play Console, hingga saat ini aplikasi PaTik Bali mendapatkan rata-rata rating 4,27 pada skala 5 . Perkembangan rating kumulatif perhari dapat dilihat pada Gambar 7.

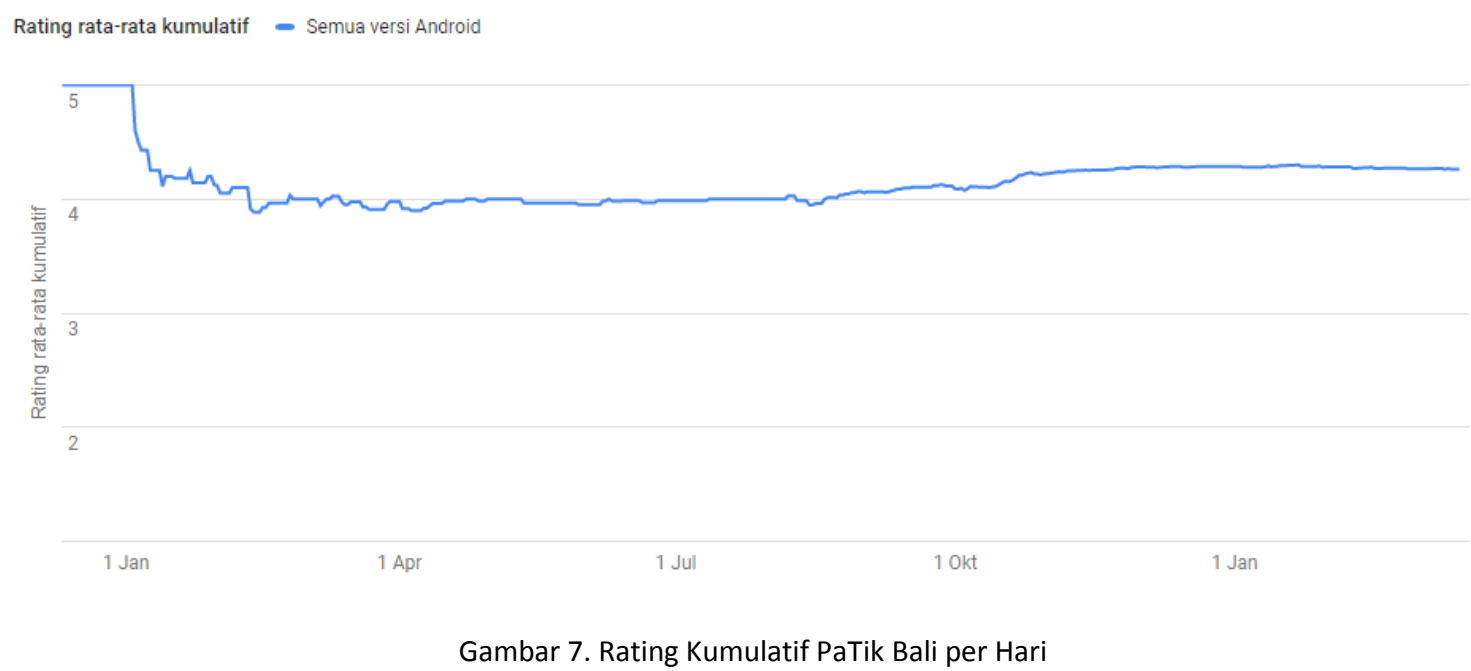

Pada awal kemunculannya, aplikasi PaTik Bali hanya menggunakan aksara bali untuk setiap tombol keyboard, hal ini banyak mendapatkan kritik dari pengguna, titik terendah terdapat pada bulan februari yaitu 3,38 pada skala 5 . Dari semua masukan yang diberikan pengguna, perlahan aplikasi PaTik Bali mulai berbenah, beberapa kali diluncurkan update minor, yaitu perbaikan untuk menyelesaikan permasalahanpermasalahan permasalahan kecil yang disampaikan pengguna. Peningkatan rating mulai terjadi pada bulan Agustus dan September, setelah PaTik Bali mengganti warna tema, dan juga memasukkan huruf latin pada setiap tombol pada keyboardnya.

Rating aplikasi PaTik Bali tidak bisa maksimal salah satunya adalah karena permasalahan pada font atau jenis huruf yang digunakan. Aplikasi PaTik Bali menggunakan font yang sudah ditanamkan pada sistem operasi Android agar dapat digunakan dapat digunakan sebagai keyboard pada aplikasi lain. Font ini masih memiliki cukup banyak masalah. Banyak pengguna yang mengeluhkan bentuk huruf 
yang kurang tepat, sehingga memberikan rating tidak maksimal seperti pada Gambar 8. Permasalahan ini tidak dapat diatasi hanya dengan melakukan perbaikan pada PaTik Bali saja. Namun, untuk memperbaiki masalah ini, perlu melakukan pengembangan pada font aksara Bali kemudian meminta Google sebagai pengembang Android untuk memasukkan font baru tersebut ke sistem operasi Android.

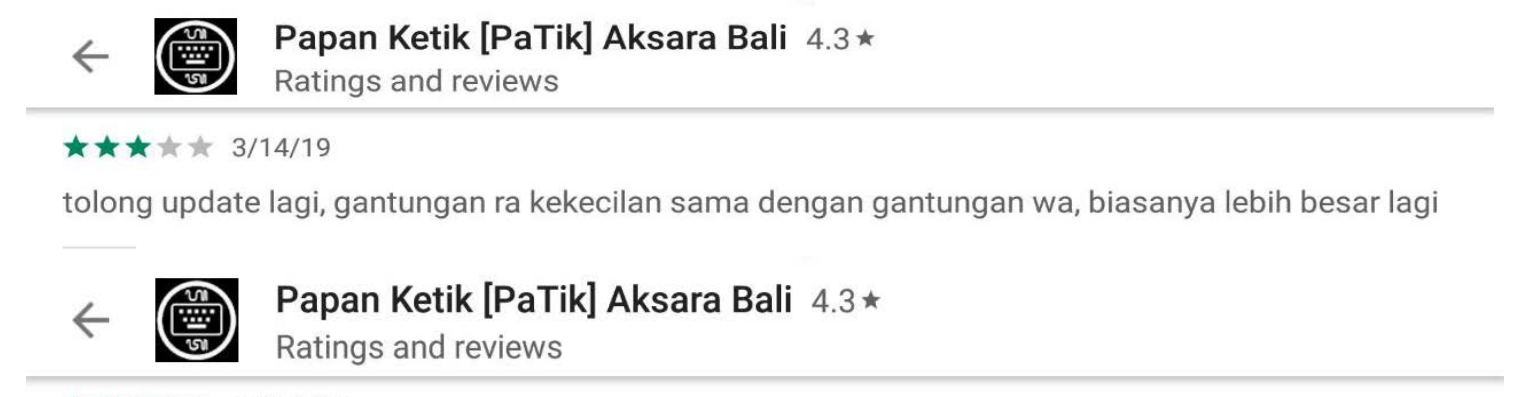

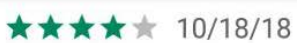

Bagus, tapi saya melihat gantungan "ra" sangat mirip dengan gantungan "wa" lebih cenderung terbaca wa contoh : prabu yvy| swabawa ajvivi।

Gambar 8. Review Pengguna

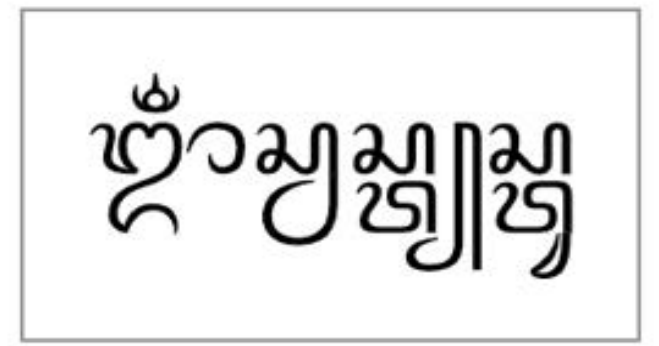

Tantular Bali

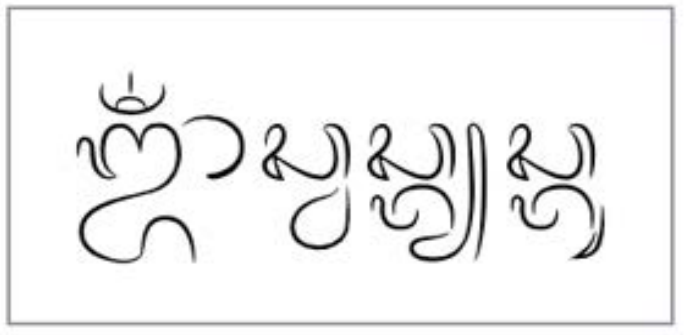

Geguratan

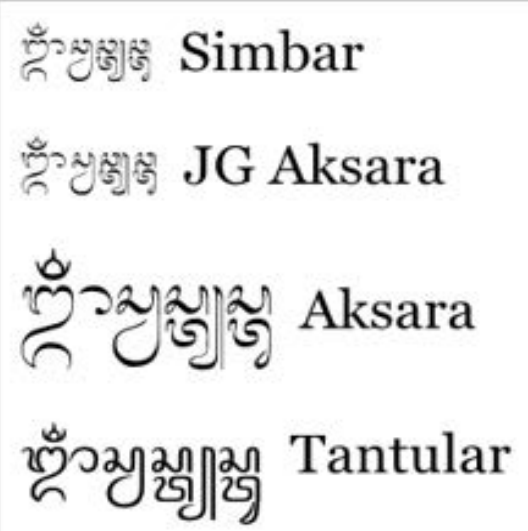

ขึ่ว2 जิ| जิ Lilitan

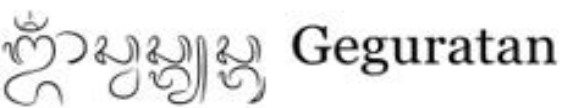

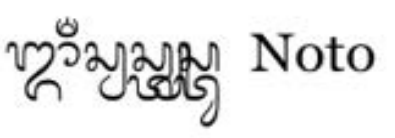

Gambar 9. Contoh Penggunaan Font Aksara Bali 
Permasalahan ini telah disampaikan pada beberapa forum Bahasa Bali seperti pada kegiatan Bulan Bahasa Bali pada bulan pebruari 2019. Pada kegiatan Bulan Bahasa Bali yang dihadiri oleh pemerintah daerah provinsi Bali, pengembang telah mendiskusikan masalah aksara Bali pada sistem operasi Android. Saat ini PaTik Bali menggunakan font yang dibuat oleh Google, yaitu Noto Sans Balinese. Kedepannya dengan adanya peraturan daerah nomor 1 tahun 2018 ini, pengembang PATIK Bali mengharapkan font yang diguanakan pada sistem operasi Android dapat diganti dengan font Tantular [6] atau font Geguratan [7] atau bahkan keduanya. Karena kedua font ini memiliki 400 glyphs. Sedangkan Noto sans Balinese hanya memliki 180 glyphs. Pada Gambar 9 terlihat contoh penggunaan font aksara Bali. Font Noto yang digunakan pada sistem operasi Android tata letaknya masih bermasalah, terlihat banyak aksara yang bertumpuk, sehingga susah dibaca. Diharapkan pemerintah bisa ikut dalam memfasilitasi pembahasan font aksara Bali ke Google untuk merubah font Noto Sans Balinese menjadi font yang sudah dikembangkan oleh penggiat aksara Bali.

\section{KESIMPULAN}

Berdasarkan penelitian yang telah dilakukan, maka terdapat beberapa kesimpulan yang didapatkan, yaitu:

1. Secara umum aplikasi PaTik Bali dapat diterima dimasyarakat mendapatkan ratarata rating 4,27 pada skala 5

2. Total pengegguna PaTik Bali terus bertambah, terutama setelah diluncurkan versi 2.0 dan adanya sosialisasi secara tecara terus menerus.

3. Terdapat beberapa kesalahan dalam penulisan aksara Bali yang diakibatkan oleh keterbatasan font aksara Bali yang disediakan oleh sistem operasi Android.

4. Dibutuhkan campur tangan pemerintah untuk mengembangkan Font yang terdapat pada sistem Operasi Android

\section{DAFTAR PUSTAKA}

[1] S. Wilian, "Bahasa Minoritas, Identitas Etnik, dan Kebertahanan Bahasa: Kasus Bahasa Sumbawa di Lombok," Masy. Linguist. Indones., vol. 23, no. 1, pp. 89102, 2005.

[2] P. B. Gubernur Bali, Peraturan Daerah Provinsi Bali Nomor 1 Tahun 2018 Tentang Bahasa, Aksara, dan Sastra Bali. Indonesia, 2018.

[3] C. R. A. Pramartha and I. B. Gede Dwidasmara, "The composition approach nonQWERTY keyboard for Balinese script," in 2014 IEEE Canada International Humanitarian Technology Conference - (IHTC), 2014, pp. 1-4.

[4] StatCounter.com, "Top 8 Desktop, Mobile \& Tablet Operating System in Indonesia from april 2015 to april 2016," 2015. [Online]. Available: http://gs.statcounter.com/\#desktop+mobile+tablet-os-ID-monthly-201504-201604bar. [Accessed: 20-May-2016].

[5] I. B. A. I. Iswara, P. P. Santika, and I. N. S. W. Wijaya, "RANCANG BANGUN PAPAN KETIK ANDROID AKSARA BALI DENGAN PERBAIKAN PASANG AKSARA OTOMATIS," 2018.

[6] A. B. Perdana, I. B. K. Sudarma, and A. Budiarto, "Font Tantular." 2015.

[7] I. B. K. Sudarma and A. Budiarto, "Font Geguratan." 2015. 
66 | Ida Bagus Ary Indra Iswara, Putu Praba Santika, I Nyoman Saputra Wahyu Wijaya 